\title{
The mediating role of sleep quality in the association between nocturia and health- related quality of life
}

\author{
Edmond Pui Hang Choi ${ }^{1 *}$ D, Eric Yuk Fai Wann ${ }^{2,3}$, Jojo Yan Yan Kwok', Weng Yee Chin² and Cindy Lo Kuen Lam²
}

\begin{abstract}
Background: Even though the negative impacts of nocturia on sleep quality and health-related quality of life (HRQOL) have been documented in previous research, their interrelationship has been poorly studied. This study aimed to explore whether nocturia would affect sleep quality, which in turn affects HRQOL.

Methods: Participants aged 40 and above were randomly recruited from a Hong Kong public primary care clinic. Participants were asked to report the average number of nocturia (waking up at night to void) pisodes per night over a 1-month period. The Pittsburgh Sleep Quality Index (PSQI) and the 12-Item Short Form Health Survey version 2 (SF-12 v2) were administered. The mediation analysis was tested using multistage regression approach and bootstrap method.

Results: Of the 500 subjects who completed the survey, 31.2\% reported symptomatic nocturia (having $\geq 2$ nocturia episodes per night), and 60.4\% experienced poor sleep quality (a PSQI global score > 5). Respondents with symptomatic nocturia had a poorer HRQOL in the domains of physical functioning (PF), role physical (RP) and social functioning (SF), general health (GH), vitality (VT) and physical component summary (PCS) of the SF-12 v2 than those without. Compared with the respondents without poor sleep quality, those with poor sleep quality had poorer HRQOL across all domains and summaries of the SF-12 v2. Mediation analysis found that sleep quality fully mediated the association between nocturia and the PF, RP and SF domains of the SF-12 V2, respectively, and partially mediated the association between nocturia and the GH, VT and PCS domains of the SF-12 V2, respectively.
\end{abstract}

Conclusions: We found that sleep quality mediated the association between nocturia and HRQOL. To enhance the $\mathrm{HRQOL}$ of patients with nocturia, clinicians should not only focus on nocturia symptoms, but also on their sleep quality.

Keywords: Health-related quality of life, Mediation, Nocturia, Sleep quality

\section{Background}

Nocturia is the most common among lower urinary tract symptoms [1]. An epidemiological study conducted in the United States (US), the United Kingdom (UK) and Sweden found that among people aged $\geq$ 40 years, the prevalence of having $\geq 2$ nocturia episodes per night was $28 \%$ for men and $34 \%$ for women [2]. A study in Asia also found that the prevalence of having $\geq 2$ nocturia episodes per night was $36 \%$ among people aged $\geq 40$ years [3].

\footnotetext{
* Correspondence: h0714919@connect.hku.hk

${ }^{1}$ School of Nursing, University of Hong Kong, 4/F, William M.W. Mong Block, 21 Sassoon Road, Pokfulam, Hong Kong

Full list of author information is available at the end of the article
}

The impact of nocturia is not trivial. Studies in the US [4] and Sweden [5] also found that nocturia negatively affects health-related quality of life (HRQOL) as measured by the Short Form-36 Health Survey (SF-36). Notwithstanding, poor sleep quality is a common complaint among people with nocturia [6]. A study in the US reported that poor sleep quality can have a serious impact on the ability to function and daytime functioning, leading to impaired HRQOL $[6,7]$.

Even though the negative impacts of nocturia on sleep quality and HRQOL have been documented in previous research [6], their interrelationship has been poorly studied. In fact, a study of a Dutch population found that the impacts of nocturia on HRQOL became statistically

(c) The Author(s). 2019 Open Access This article is distributed under the terms of the Creative Commons Attribution 4.0 International License (http://creativecommons.org/licenses/by/4.0/), which permits unrestricted use, distribution, and 
insignificant after controlling for sleep quality. Besides, in a qualitative study in the US, respondents indicated that nocturia affected their functioning and wellbeing in daytime because of poor sleep quality [8]. These studies imply that the relationship between nocturia and HRQOL could be mediated by sleep quality. A better understanding of their interrelationship could help clinicians better manage patients with nocturia by informing the development of interventions to address their multidimensional needs.

Therefore, the objective of the present study was to explore the interrelationship between nocturia, sleep quality and HRQOL. We hypothesized that sleep quality mediated the relationship between nocturia and HRQOL.

\section{Methods}

\section{Study design}

This was a cross-sectional study.

\section{Setting}

The study participants were recruited from a governmentfunded primary care clinic of the Hospital Authority, Hong Kong. The Hospital Authority is a statutory body responsible for approximately $80 \%$ of chronic disease care locally.

\section{Participants}

The inclusion criteria were primary care patients aged $\geq 40$ years. The exclusion criteria included the inability to understand Cantonese, refusal to participate, pregnancy, having had a urinary tract infection in the past 4 weeks or being too ill to give consent.

\section{Sampling}

Random sampling was used. To avoid disturbing service delivery and doctors' consultations and to ensure that no patients were missed, a consultation room was randomly selected for each half-day session. Randomisation of the consultation rooms was performed prior to data collection and in discussion with the clinic staff to ensure that the room would be used for medical consultations. After randomisation, consecutively presenting patients in that consultation room were approached and recruited by a trained fieldworker. All eligible patients were invited to participate in the study.

\section{Study outcomes and study instruments}

To measure nocturia (the independent variable), the study participants were asked to report the average number of nocturia episodes per night over a 1-month period on a 5-point Likert scale (0, 1, 2, 3 or $\geq 4$ episodes per night). To make our study findings more comparable to those of previous studies [3], nocturia was defined as having $\geq 2$ episodes per night. We used a cut-off of 2 voiding episodes per night for two reasons. First, using the International Continence Society's definition of at least one episode per night could easily lead to a very high prevalence of nocturia [3]. Some authors also suggest that using a cut-off of 2 voiding episodes per nigh are more clinically relevant $[9,10]$. Our participants were divided into 2 groups using this cut-off: (i) no nocturia (0 to 1 episode per night) and (ii) having nocturia ( $\geq 2$ episodes per night).

To measure sleep quality (the proposed mediator), the Chinese version of the Pittsburgh Sleep Quality Index (PSQI) was used [11]. It is the most commonly used generic measure in both clinical and research settings, with strong positive evidence for its psychometric properties [12]. The recall period of the PSQI was 1 month. Nineteen individual items generated 7 component scores: subjective sleep quality, sleep latency, sleep duration, habitual sleep efficiency, sleep disturbances, use of sleeping medication and daytime dysfunction. The component scores ranged from 0 to 3 . These 7 component scores were then summed to generate the global score of subjective sleep quality. The global score ranged from 0 to 21, with a higher score indicating poorer subjective sleep quality. A study in Hong Kong supported this unidimensional structure [13]. Additionally, a study on Chinese people suggested that a global score $>5$ with a sensitivity of $98 \%$ could be used to identify people with poor sleep quality [11].

The Hong Kong Chinese version of the 12-Item Short Form Health Survey version 2 (SF-12 v2) was used to measure generic HRQOL (the dependent variable). It comprises 8 domains: physical functioning (PF), role limitation due to physical problems (RP), bodily pain (BP), general health $(\mathrm{GH})$, vitality $(\mathrm{VT})$, social functioning $(\mathrm{SF})$, role limitation due to emotional problems (RE) and mental health (MH). The scores range from 0 to 100 . The SF12 v2 can also be summarised into 2 norm-based summary scores: physical and mental component summaries (PCS and MCS, respectively). Higher SF-12 v2 scores indicate better generic HRQOL. The SF-12 v2 has been validated and is used extensively in Hong Kong [14-16].

\section{Statistical analysis}

First, descriptive statistics were used to describe the prevalence of symptomatic nocturia ( $\geq 2$ episodes per night) and poor sleep quality (a PSQI global score > 5). Second, the association between nocturia and sleep quality was explored by multiple linear regression (using the continuous PSQI global score as the outcome) and multiple logistic regression (using the dichotomous variable: a global score $\leq 5$ vs. a global score $>5$ ). The regression models were controlled for age, gender, marital status and employment status. Third, independent $t$-tests 
were used to compare the SF-12 v2 score (i) between the participants with nocturia and those without and (ii) between the participants with sleep disturbance and those without. Fourth, the PROCESS macro version 3.4 developed by Hayes was used to conduct the mediation analysis [17]. In the macro, the following regression models were used:

1. HRQOL (dependent variable) was regressed on nocturia ( $\geq 2$ episodes per night).

2. Sleep quality (mediators) was regressed on nocturia. We used the global score the PSQI (a continuous variable) in the analysis.

3. HRQOL was regressed on sleep quality.

4. HRQOL was regressed on both sleep quality and nocturia simultaneously.

To further validate the indirect effects (i.e. nocturia affected sleep quality, which in turn affected HRQOL), the bootstrap method was used to obtain the point estimate. This method is more powerful than the Sobel test [18]. The point estimates were based on 10,000 bootstrap samples, and 95\% confidence intervals (CI) were constructed. An indirect effect was considered significant if the CI did not contain 0 .

Figure 1 shows the proposed mediation model. Fig. 1 shows the total effect of nocturia on HRQOL, without considering the mediator (i.e. sleep quality). $c$ is the regression coefficient in a linear regression model predicting HRQOL from nocturia.

In Fig. 1, $a$ is the regression coefficient in a linear regression model predicting sleep quality from nocturia whilst $b$ and $c^{\prime}$ are the regression coefficients in a linear regression model predicting HRQOL from sleep quality and nocturia, respectively. $c^{\prime}$ quantifies the direct effect of nocturia on HRQOL whereas the product of $a$ and $b$ (point estimate) quantifies the indirect effect of nocturia on HRQOL through sleep quality. In other words, $c=c^{\prime}+$ $a b$. The product $a$ and $b$ can be interpreted as the amount by which two cases who differ by one unit on nocturia are expected to differ on HRQOL though the effect of nocturia on sleep quality.

Full mediation is the case in which an independent variable no longer affects a dependent variable after a mediator has been controlled. In other words, $c^{\prime}$ is no longer statistically significant. Partial mediation is the case in which the path from independent variable to dependent variable is reduced in absolute size after controlling a mediator but $c^{\prime}$ is still statistically significant.

\section{Sample size calculation}

The study by Kobelt, Borgström [5] reported that Cohen's d effect size difference of the VT score between people with nocturia and those without was 0.67 . Using this as our reference, a sample of at least 72 participants (36 in each group) was needed to detect a moderate effect size difference by independent $t$-test with $80 \%$ power (alpha $=0.05$, two-tailed).

\section{Ethics}

The study protocol was approved by the institutional review board: HKWC (UW19-179). Written informed consent was obtained from all individual participants included in the study.

\section{Results}

\section{Participants}

Of the 815 primary care patients who were approached, 20 patients did not meet the inclusion criteria, and 295 patients refused to join the study. As a result, 500

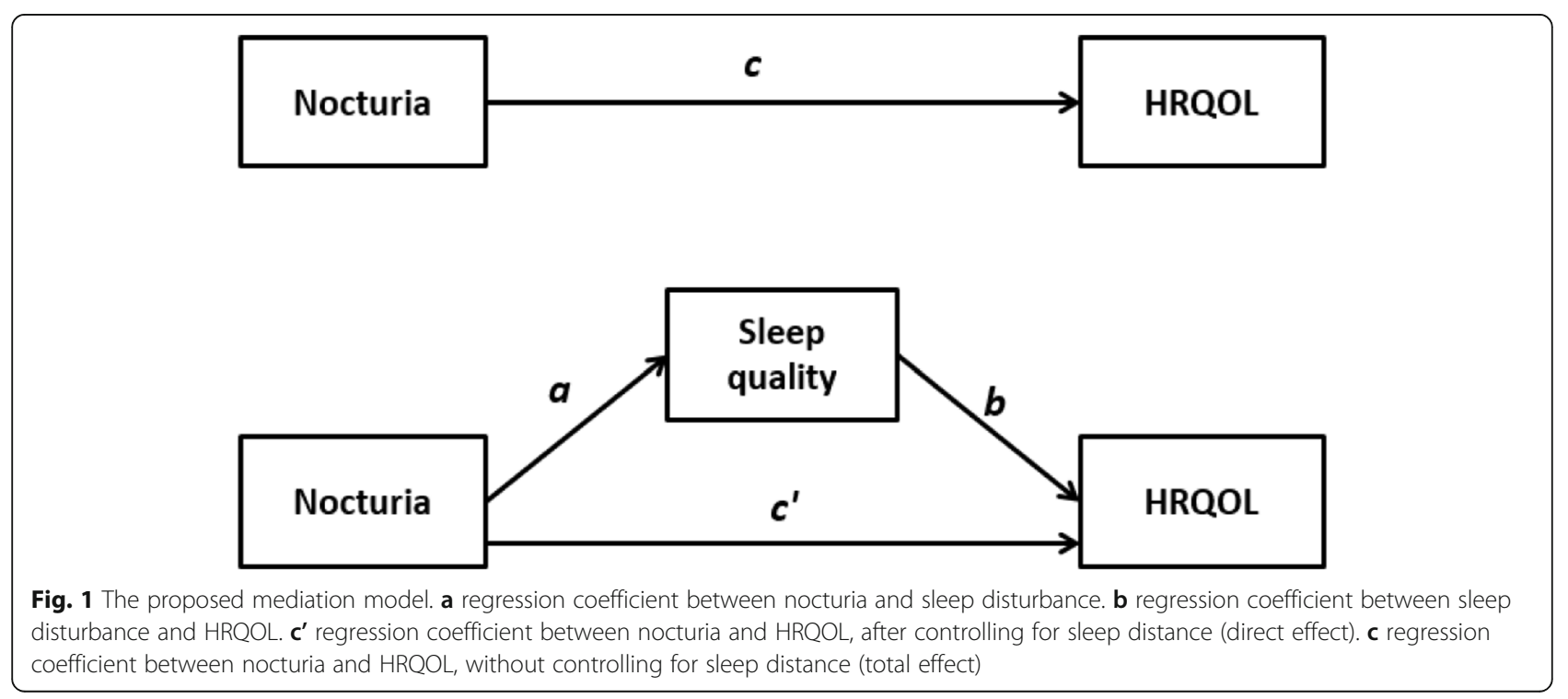


patients joined our study. The mean age was 57.5 years (standard deviation: 9.8), of which $57.4 \%$ were female patients. Among the participants, $74 \%$ were married, and $59.6 \%$ were in active employment. Table 1 shows the demographic characteristics of the participants.

\section{Prevalence of Nocturia and sleep quality and their association}

Among the participants, $80 \%$ reported having $\geq 1$ nocturia episode per night, $31.2 \%$ indicated having $\geq 2$ nocturia episodes per night, and $11.2 \%$ indicated that they had had $\geq 3$ nocturia episodes per night. Furthermore, $60.4 \%$ of the participants had poor sleep quality. Table 1 shows the descriptive statistics of the study outcomes. Having $\geq 2$ nocturia episodes per night increased the likelihood of having poor sleep quality, with an adjusted odds ratio (aOR) of 2.06 and $\beta$ of 1.64 . Table 2 shows the results of the regression analysis.

Table 1 Socio-demographics and the prevalence of nocturia and poor sleep quality $(N=500)$

\begin{tabular}{|c|c|}
\hline \multicolumn{2}{|l|}{ Socio-demographics } \\
\hline Mean age (SD) & $57.5(9.8)$ \\
\hline & N (\%) \\
\hline \multicolumn{2}{|l|}{ Gender } \\
\hline Women & $287(57.4 \%)$ \\
\hline Men & $213(42.6 \%)$ \\
\hline \multicolumn{2}{|l|}{ Marital status } \\
\hline Not married & $130(26.0 \%)$ \\
\hline Married & $370(74.0 \%)$ \\
\hline \multicolumn{2}{|l|}{ Employment status } \\
\hline Working & $202(40.4 \%)$ \\
\hline Not working & $298(59.6 \%)$ \\
\hline \multicolumn{2}{|l|}{ Nocturia } \\
\hline$\geq 1$ episode per night & $400(80.0 \%)$ \\
\hline$\geq 2$ episode per night & $156(31.2 \%)$ \\
\hline$\geq 3$ episode per night & $56(11.2 \%)$ \\
\hline \multicolumn{2}{|l|}{ Sleep quality } \\
\hline Mean PSQI global score (SD) & $7.1(3.7)$ \\
\hline PSQI global score $>5$ & $302(60.4 \%)$ \\
\hline \multicolumn{2}{|l|}{ Comorbidities } \\
\hline Hypertension & $250(50.0 \%)$ \\
\hline Diabetes & $75(15.2 \%)$ \\
\hline Heart disease & $58(11.6 \%)$ \\
\hline Stroke & $11(2.2 \%)$ \\
\hline Respiratory disease & $30(6.0 \%)$ \\
\hline Benign prostatic hyperplasia & $33(15.5 \%) \wedge$ \\
\hline
\end{tabular}

Abbreviation; SD standard deviation, PSQI Pittsburgh Sleep Quality Index Note: ^ male participants only
Compared with the patients with $<2$ nocturia episodes per night, the patients with $\geq 2$ nocturia episodes per night had poorer HRQOL as measured by the SF-12 v2 domains PF (effect size $=0.34$ ), RP (effect size $=0.21$ ), GH (effect size $=0.60)$, VT (effect size $=0.30)$ and SF (effect size $=0.22$ ) and the SF-12 v2 PCS (effect size $=0.38$ ). Compared with the patients with no sleep problems, the patients with poor sleep quality had poorer HRQOL in all 8 domains and the PCS and MCS of the SF-12 v2. The difference in effect size ranged from 0.80 for the MCS to 0.41 for the PF domain. Table 3 shows the results of the independent $t$-tests.

\section{Mediation models}

We only conducted the mediation analysis for the PF, $\mathrm{RP}, \mathrm{GH}, \mathrm{VT}$ and SF domains and the PCS because we only found HRQOL score differences in these domains between patients with and without $\geq 2$ nocturia episodes per night. After controlling for sleep quality, the impacts of nocturia on HRQOL as measured by the PF $(\beta=-$ $3.84, \quad p$-value $=0.089), \quad R P(\beta=-1.20, \quad p$-value $=0.593)$ and SF $(\beta=-2.48, p$-value $=0.265)$ domains were no longer statistically significant, supporting the full mediation models. On the contrary, the direct effects of nocturia on HRQOL as measured by the GH $(\beta=-10.59, p$ value $<0.01)$ and VT $(\beta=-4.60$, $\mathrm{p}$-value $<0.05)$ domains and PCS $(\beta=-1.69$, p-value $<0.05)$ were still statistically significant, but the coefficients of the direct effect were smaller than those of the total effect: $\mathrm{GH}(\beta=-13.90$, $\mathrm{p}$ value $<0.01)$, VT $(\beta=-9.08, \mathrm{p}$-value $<0.01)$ and PCS ( $\beta=-2.66$, p-value $<0.01)$, thus supporting the partial mediation models. For all the mediation models, the point estimate was negative and statistically different from 0 (i.e. the $95 \%$ CI did not contain 0). The results supported our hypothesis that sleep quality was the mediator between nocturia and HRQOL. Table 4 and Fig. 2 show the results of the mediation analysis.

\section{Discussion}

In our study, we found that sleep quality was a mediator in the association between nocturia and HRQOL, suggesting that nocturia affects sleep quality, which in turn affects HRQOL. One possible mechanism is that nocturia affects slow-wave sleep (SWS), which is associated with daily process of recuperation [19]. It was reported that adults who wake early to void during their first two sleep cycles spend 34\% less time in SWS than adults who sleep undisturbed through two sleep cycles [20]. Moreover, disruption in sleep continuity throughout the night can also reduce SWS. Despite equivalent total sleep times, people who experience repeated awakenings during the night spend less time in SWS than people with uninterrupted sleep [20]. It was reported that interruption of SWS leads to fatigue, increased discomfort 
Table 2 regression models to explore the association between nocturia and poor sleep quality

\begin{tabular}{|c|c|c|c|c|c|c|}
\hline & \multicolumn{3}{|c|}{ Multiple logistic regression $\wedge$} & \multicolumn{3}{|c|}{ Multiple linear regression $\wedge \wedge$} \\
\hline & $\mathrm{aOR}$ & $95 \% \mathrm{Cl}$ & $p$-value & $\beta$ & $95 \% \mathrm{Cl}$ & $p$-value \\
\hline Nocturia $\geq 2$ & 2.06 & $(1.34,3.16)$ & $<0.01$ & 1.64 & $(0.91,2.38)$ & $<0.01$ \\
\hline Age & 0.99 & $(0.97,1.01)$ & 0.35 & -0.02 & $(-0.06,0.01)$ & 0.20 \\
\hline Gender & 0.90 & $(0.62,1.32)$ & 0.59 & -0.70 & $(-1.37,-0.03)$ & $<0.05$ \\
\hline Marital status & 0.80 & $(0.52,1.22)$ & 0.30 & -0.61 & $(-1.35,0.14)$ & 0.11 \\
\hline \multirow{2}{*}{ Employment status } & 1.24 & $(0.79,1.92)$ & 0.35 & 0.21 & $(-0.57,0.99)$ & 0.60 \\
\hline & \multicolumn{3}{|c|}{ Nagelkerke $R^{2}: 0.037$} & & $R^{2} 0.054$ & \\
\hline
\end{tabular}

$\wedge$ : the dependent variable of the model is dichotomous (PSQI global score $\leq 5$ vs. 5PSQI global score $>5$ )

$\wedge \wedge$ : the dependent variable of the model is continuous (PSQI global score)

Abbreviation: $a O R$ adjusted odds ratio, $C l$ confidence interval, PSQI Pittsburgh Sleep Quality Index, SD standard deviation

and a decreased pain threshold [21]. The findings of this mediation analysis provide additional depth to previous research. For example, the respondents in a qualitative study reported that nocturia impaired sleep in terms of quantity and quality. The next day, the respondents would feel very tired due to a lack of sleep. As a result, they could not concentrate at work [8]. An epidemiological study among a Dutch population found that the impacts of nocturia on HRQOL became statistically insignificant when sleep quality was put in a regression model [22]. No doubt, the findings that nocturia affects sleep and HRQOL are certainly not new. However, previous studies only examined the negative impacts of nocturia on sleep and HRQOL in isolation [4].

Given that nocturia itself is not life threatening, the treatment outcomes should aim to alleviate its negative impacts on daily life. Understanding the interrelationship between nocturia, sleep quality and HRQOL can therefore guide clinical practice. One important implication of our findings is that, to optimize the HRQOL of patients with nocturia, behavioural interventions for nocturia should also target sleep quality in these patients. For example, we might incorporate cognitivebehavioural theory to enhance sleep hygiene among patients suffering from nocturia.

Table 3 The impacts of nocturia and poor sleep quality on health-related quality of life

\begin{tabular}{|c|c|c|c|c|c|c|}
\hline & \multicolumn{3}{|l|}{ Nocturia } & \multicolumn{3}{|l|}{ Sleep disturbance } \\
\hline & $\begin{array}{l}\text { (Nocturia }< \\
\text { 2) }\end{array}$ & (Nocturia $\geq 2$ ) & $\begin{array}{l}\text { Cohen's d Effect } \\
\text { size }\end{array}$ & $\begin{array}{l}\text { No } \\
\text { (PSQI global score } \leq \\
\text { 5) }\end{array}$ & $\begin{array}{l}\text { Yes } \\
\text { (PSQl global score > } \\
\text { 5) }\end{array}$ & $\begin{array}{l}\text { Cohen's d Effect } \\
\text { size }\end{array}$ \\
\hline & Mean (SD) & Mean (SD) & & Mean (SD) & Mean (SD) & \\
\hline \multicolumn{7}{|l|}{$S F-12$ V2 $*$} \\
\hline Physical Functioning & $87.39(20.80)$ & $\begin{array}{l}79.22(27.09) \\
* *\end{array}$ & 0.34 & $90.31(19.65)$ & $81.27(24.67) * *$ & 0.41 \\
\hline Role Physical & $79.80(21.70)$ & $74.76(25.46) *$ & 0.21 & $84.85(19.62)$ & $73.88(24.07) * *$ & 0.50 \\
\hline Bodily Pain & $66.98(27.20)$ & $63.62(29.28)$ & 0.12 & $74.24(26.11)$ & $60.51(27.70) * *$ & 0.51 \\
\hline General Health & $54.25(26.43)$ & $\begin{array}{l}38.68(25.38) \\
* *\end{array}$ & 0.60 & $57.36(25.84)$ & $44.02(26.58) * *$ & 0.51 \\
\hline Vitality & 59.04 (23.69) & $\begin{array}{l}51.76(24.61) \\
* *\end{array}$ & 0.30 & $66.41(22.43)$ & $50.42(23.23) * *$ & 0.70 \\
\hline Social Functioning & $81.29(22.43)$ & $75.96(26.77) *$ & 0.22 & $88.38(17.20)$ & $73.83(26.00) * *$ & 0.66 \\
\hline Role Emotional & 79.54 (20.91) & $75.00(25.36)$ & 0.20 & $87.56(17.11)$ & $71.92(23.40) * *$ & 0.76 \\
\hline Mental Health & 69.95 (17.79) & $66.27(22.02)$ & 0.18 & $76.26(16.42)$ & $63.91(19.44) * *$ & 0.69 \\
\hline $\begin{array}{l}\text { Physical Component } \\
\text { Summary }\end{array}$ & $48.81(8.19)$ & $45.48(9.24) * *$ & 0.38 & $49.83(7.20)$ & $46.38(9.27)^{* *}$ & 0.42 \\
\hline $\begin{array}{l}\text { Mental Component } \\
\text { Summary }\end{array}$ & $50.81(9.48)$ & $48.99(11.15)$ & 0.18 & $54.63(8.02)$ & $47.29(10.21) * *$ & 0.80 \\
\hline
\end{tabular}


Table 4 Mediation analysis

\begin{tabular}{llr}
\hline & Point estimate of indirect effect & $95 \% \mathrm{Cl} \wedge$ \\
\hline Physical Functioning & -2.73 & $-4.46,-1.27$ \\
Role Physical & -3.44 & $-5.50,-1.72$ \\
General Health & -3.31 & $-5.21,-1.66$ \\
Vitality & -4.48 & $-6.94,-2.29$ \\
Social Functioning & -4.57 & $-7.06,-2.37$ \\
Physical Component Summary score & -0.98 & $-1.65,-0.44$
\end{tabular}

$\wedge$ : Bootstrap confidence interval: if the $95 \%$ confidence interval $(\mathrm{Cl})$ does not contain zero, the mediation (indirect effect) is significant. The analysis was adjusted by age, gender, marital status and employment status

Abbreviation: $\mathrm{Cl}$ confidence interval

Poor sleep quality was very common in our sample. Using the PSQI global score with $>5$ as the cut-off, we found that $60 \%$ of our participants were suffering from poor sleep quality. Our prevalence was much higher than the prevalence reported in the population-based studies in Hong Kong (PSQI global score $>5: 39.4 \%$ ) by Wong and Fielding [23], Germany (PSQI global score > 5: 36\%) by Hinz, Glaesmer [24] and China (PSQI global score $>5: 26.6 \%$ ) by Tang, Liao [25]. The high prevalence found in the present study could be explained by the characteristics of our study population. Compared with community samples, our study population in primary care were likely to include participants with multimorbidities [26]. It was found that multi-morbidities were associated with insomnia [27].

Almost one third $(31.2 \%)$ of our primary care patients were suffering from nocturia. This prevalence is similar to those reported in Korea [28], the US, the UK and Sweden [2]. These collective findings suggest that the burden of nocturia is common and universal across different populations. Moreover, the high prevalence of nocturia found in our primary care patients implies that the problems were likely overlooked and untreated.

In our study, having $\geq 2$ nocturia episodes per night was associated with poorer HRQOL. It also appeared that nocturia had more negative impacts on the physical aspects of HRQOL than the mental aspects. However, our findings were different from those reported by Kupelian and colleagues [29]. This US study found that nocturia affected both the physical and mental aspects of HRQOL as measured by the SF-12. In fact, HRQOL and symptom perception are culturally specific. A qualitative study in the UK found that patients with urinary problems had concerns about the aetiology of their symptoms as well as disease progression. In some cases, patients even thought that their urinary problems were related to the possibility of cancer [30]. In contrast, a recent qualitative study in Hong Kong found that urinary problems had no psychological effects on the majority of Chinese patients. These patients indicated

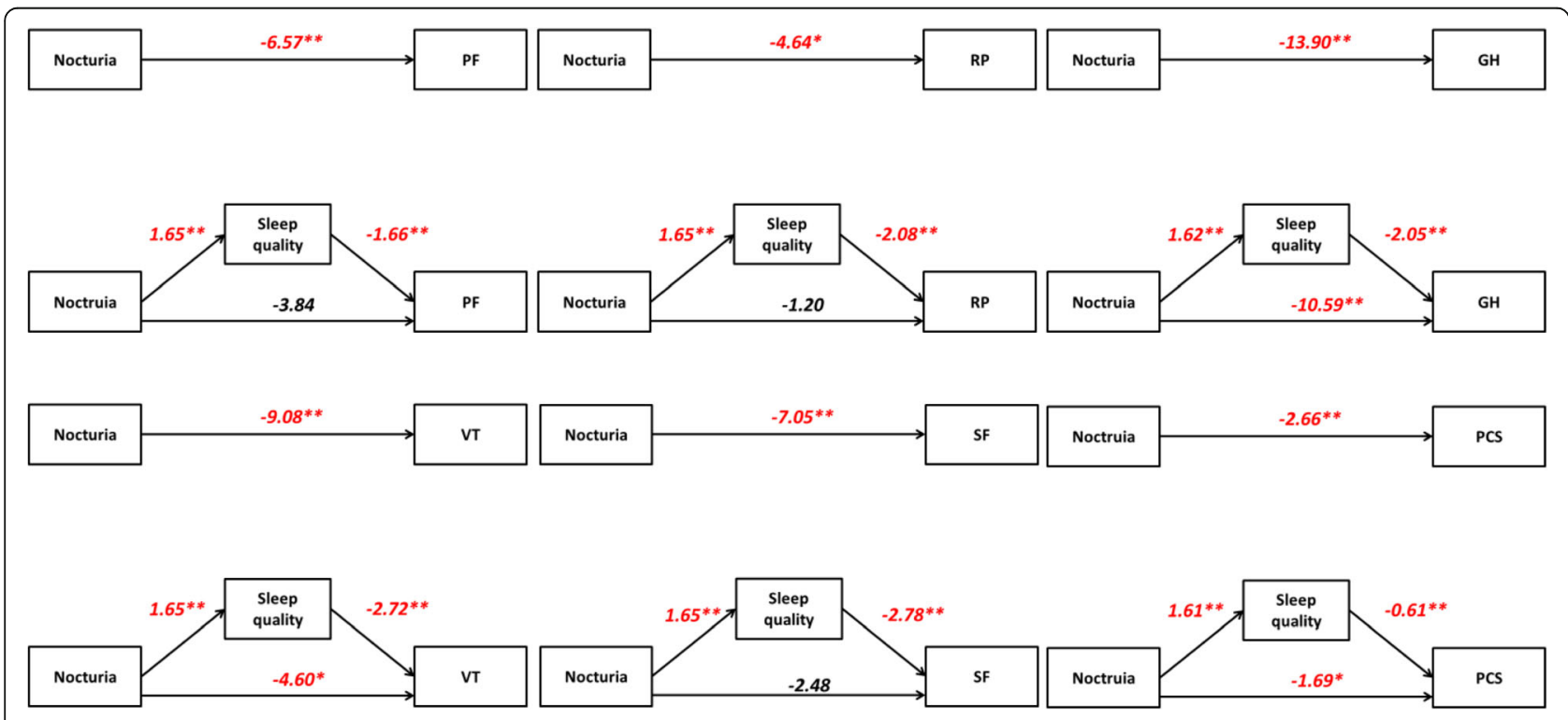

Fig. 2 Result of the mediation analysis. ${ }^{*}$ p-value $<0.05,{ }^{* *}$ p-value $<0.01$ 
that urinary problems were just a consequence of normal ageing [31]. Even though some people reported negative psychosocial impacts associated with urinary problems, the psychological burden was merely related to embarrassment, inconvenience and restrictions on social activities [31]. These qualitative findings (i.e. urinary problems as a normal part of the ageing process and urinary problems affecting social and physical activities) by Suen and colleagues [31] echoed our findings that nocturia among the participants in our study mainly affected their physical functioning, social functioning and general health, all to the detriment of the overall physical aspects of their HRQOL.

Poor sleep quality in our study was associated with poor HRQOL across all domains of the SF-12 v2. A study of an older population in the US also found that sleep problems negatively affected all 8 domains and the PCS and MCS of the SF-36 [32]. In addition, another study found that insomnia and its associated daytime sleepiness impaired cognitive functioning such as concentration, memory, reasoning and problem solving, as well as the ability to perform ordinary daily tasks [33]. Qualitative studies have also reported that sleep problems have a pervasive impact on daily life [34], and the problems are unpleasant and worrying [35]. In our study, we found that the participants who reported sleep disturbance had poorer mental aspects of HRQOL than those without, with a large effect size. It is suggested that sleep deprivation could induce dysphoria, increase irritability and lower frustration tolerance. Experimental studies have found that sleep deprivation can lead to a deterioration in mood and increased reactions to negative emotional information [36]. Besides, based on the Cohen's d effect sizes found in the present study, it appeared that poor sleep quality had more negative impacts on all aspects of HRQOL (except for the GH domain of the SF-12 v2) than nocturia did. For example, the effect size difference of the SF-12 v2 MCS between people with poor sleep quality than those without was 0.80 while it was 0.18 between people with nocturia than those without. The effect size difference of the SF-12 v2 PCS between people with poor sleep quality than those without was 0.42 while it was 0.38 between people with nocturia than those without. Our findings were in line with those found in Japan [37].

Our study had some limitations. First, given its crosssectional design, causality could not be provided in the present study. Longitudinal studies are needed to make causal inferences. In fact, it is possible that people with insomnia will go to the toilet just because they can't sleep. Our findings should be therefore interpreted with caution. Second, all the study outcomes were selfreported and may therefore be susceptible to biases such as recall bias and social desirability bias. Third, our study was conducted in public sector primary care setting. Our study findings might therefore not be transferable to the general population. Fourth, we had a high nonresponse rate of our study. It might lead to a nonresponse bias. A common reason to refuse the study was that patients did not want to spend extra time to fill out the questionnaire. It implied that waiting room screening might not be an optimal way to recruit primary care patients. Future studies should consider other strategies such as telephone follow-up interview so that patients can finish the questionnaire at their convenience.

\section{Conclusions}

Sleep disturbance as a mediator in the association between nocturia and HRQOL suggests that nocturia not only has a direct relationship with HRQOL, but also an indirect relationship via sleep disturbance. Clinicians wanting to improve patients' HRQOL should not only focus on the patients' nocturia symptoms, but also on their sleep quality.

\begin{abstract}
Abbreviations
aOR: adjusted Odds Ratio; BP: Bodily Pain; GH: General Health; HRQOL: Health-related Quality of Life; MCS: Mental Component Summaries; MH: Mental Health; OR: Odds Ratio; PCS: Physical Component Summaries; PF: Physical Functioning; PSQI: Pittsburgh Sleep Quality Index; RE: Role Limitation due to Emotional Problems; RP: Role Limitation due to Physical Problems; SF: Social Functioning; SF-12 v2: Short Form-12 Health Survey version 2; SF-36: Short Form-36 Health Survey; UK: United Kingdom; US: United States; VT: Vitality
\end{abstract}

\section{Acknowledgments}

The authors would like to thank Prof Rainbow Ho and Mr. Ted Fong for the Chinese version of the PSQI.

\section{Author's contribution}

EC was responsible for funding acquisition, data collection, data analysis and manuscript writing. EW provided statistical support and manuscript writing. $\mathrm{JK}$ reviewed and edited the manuscript. WC and CL provided expert advice and edited and reviewed the manuscript. All authors read and approved the final manuscript.

\section{Funding}

The study was supported by Seed Fund for Basic Research (no: 201804159013), The University of Hong Kong.

Availability of data and materials

The datasets used in the current study are available from the corresponding author on reasonable request.

\section{Ethics approval and consent to participate}

The study protocol was approved by the institutional review board: HKWC (UW19-179). All procedures performed in studies involving human participants were in accordance with the ethical standards of the institutional and/or national research committee and with the 1964 Helsinki declaration and its later amendments or comparable ethical standards.

\section{Consent for publication}

Written informed consent was obtained from all individual participants included in the study.

Competing interests

All authors declare they have no conflict of interest. 


\section{Author details}

'School of Nursing, University of Hong Kong, 4/F, William M.W. Mong Block 21 Sassoon Road, Pokfulam, Hong Kong. ${ }^{2}$ Department of Family Medicine and Primary Care, University of Hong Kong, Pokfulam, Hong Kong. ${ }^{3}$ Department of Pharmacology and Pharmacy, University of Hong Kong, Pokfulam, Hong Kong.

Received: 25 September 2019 Accepted: 26 November 2019

Published online: 11 December 2019

\section{References}

1. Weiss JP. Nocturia: focus on etiology and consequences. Reviews in urology. 2012;14(3-4):48.

2. Madhu C, Coyne K, Hashim H, Chapple C, Milsom I, Kopp Z. Nocturia: risk factors and associated comorbidities; findings from the Epi LUTS study. Int J Clin Pract. 2015;69(12):1508-16

3. Chapple C, Castro-Diaz D, Chuang Y-C, Lee K-S, Liao L, Liu S-P, et al. Prevalence of lower urinary tract symptoms in China, Taiwan, and South Korea: results from a cross-sectional, population-based study. Adv Ther. 2017:34(8):1953-65.

4. Coyne K, Zhou Z, Bhattacharyya S, Thompson C, Dhawan R, Versi E. The prevalence of nocturia and its effect on health-related quality of life and sleep in a community sample in the USA. BJU Int. 2003;92(9):948-54

5. Kobelt G, Borgström F, Mattiasson A. Productivity, vitality and utility in a group of healthy professionally active individuals with nocturia. BJU Int. 2003:91(3):190-5.

6. Ancoli-Israel S, Bliwise DL, Nørgaard JP. The effect of nocturia on sleep. Sleep Med Rev. 2011;15(2):91-7.

7. Darchia N, Oniani N, Sakhelashvili I, Supatashvili M, Basishvili T, Eliozishvili M, et al. Relationship between sleep disorders and health related quality of life-results from the Georgia SOMNUS study. Int J Environ Res Public Health. 2018;15(8):1588

8. Trigg A, Andersson FL, Aldhouse NV, Bliwise DL, Kitchen H. Patients' lived experiences of nocturia: a qualitative study of the evening, the night, and the next day. The Patient-Patient-Centered Outcomes Research. 2017;10(6):711-8.

9. Zumrutbas AE, Bozkurt Al, Alkis O, Toktas C, Cetinel B, Aybek Z. The prevalence of nocturia and nocturnal polyuria: can new cutoff values be suggested according to age and sex? International neurourology journal. 2016;20(4):304

10. Madersbacher S, Cornu J-N. Nocturnal polyuria: it's all about definition, and be patient! 2013

11. Tsai P-S, Wang S-Y, Wang M-Y, Su C-T, Yang T-T, Huang C-J, et al. Psychometric evaluation of the Chinese version of the Pittsburgh sleep quality index (CPSQI) in primary insomnia and control subjects. Qual Life Res. 2005:14(8):1943-52.

12. Mollayeva T, Thurairajah P, Burton K, Mollayeva S, Shapiro CM, Colantonio A The Pittsburgh sleep quality index as a screening tool for sleep dysfunction in clinical and non-clinical samples: a systematic review and meta-analysis. Sleep Med Rev. 2016:25:52-73.

13. Ho RT, Fong TC. Factor structure of the Chinese version of the Pittsburgh sleep quality index in breast cancer patients. Sleep Med. 2014;15(5):565-9.

14. Lam CL, Eileen $Y$, Gandek B. Is the standard SF-12 health survey valid and equivalent for a Chinese population? Qual Life Res. 2005;14(2):539-47.

15. Chin WY, Choi EP, Wan EY. Trajectory pathways for depressive symptoms and their associated factors in a Chinese primary care cohort by growth mixture modelling. PLoS One. 2016;11(2):e0147775

16. Wong CK, Choi EP, Chan SW, Tsu JH, Fan C, Chu PS, et al. Use of the international prostate symptom score (IPSS) in Chinese male patients with benign prostatic hyperplasia. The Aging Male. 2017;20(4):241-9.

17. Hayes AF. Introduction to mediation, moderation, and conditional process analysis: a regression-based approach: Guilford publications; 2017.

18. Shrout PE, Bolger N. Mediation in experimental and nonexperimental studies: new procedures and recommendations. Psychol Methods. 2002;7(4):422.

19. Schneider T. Stanley N. Impact of nocturia on sleep and energy european urology supplements. 2007;6(9):585-93.

20. Dani H, Esdaille A, Weiss JP. Nocturia: aetiology and treatment in adults. Nature reviews Urology. 2016;13(10):573.

21. Stanley $\mathrm{N}$. The underestimated impact of nocturia on quality of life. Eur Urol Suppl. 2005;4(7):17-9.
22. van Dijk L, Kooij D, Schellevis F, Kaptein A, Boon T, Wooning M. Nocturia: impact on quality of life in a Dutch adult population. BJU Int. 2004;93(7): 1001-4.

23. Wong WS, Fielding R. Prevalence of insomnia among Chinese adults in Hong Kong: a population-based study. Journal of sleep research. 2011; 20(1pt1):117-26.

24. Hinz A, Glaesmer H, Brähler E, Löffler M, Engel C, Enzenbach C, et al. Sleep quality in the general population: psychometric properties of the Pittsburgh sleep quality index, derived from a German community sample of 9284 people. Sleep Med. 2017;30:57-63.

25. Tang J, Liao Y, Kelly BC, Xie L, Xiang Y-T, Qi C, et al. Gender and regional differences in sleep quality and insomnia: a general population-based study in Hunan Province of China. Sci Rep. 2017:7:43690.

26. Violan C, Foguet-Boreu Q, Flores-Mateo G, Salisbury C, Blom J, Freitag M, et al. Prevalence, determinants and patterns of multimorbidity in primary care: a systematic review of observational studies. PLoS One. 2014;9(7):e102149.

27. Smagula SF, Stone KL, Fabio A, Cauley JA. Risk factors for sleep disturbances in older adults: evidence from prospective studies. Sleep Med Rev. 2016;25:21-30.

28. Yoo TK, Lee K-S, Sumarsono B, Kim S-T, Kim H-J, Lee H-C, et al. The prevalence of lower urinary tract symptoms in population aged 40 years or over, in South Korea. Investigative and clinical urology. 2018;59(3):166-76.

29. Kupelian V, Wei JT, O'Leary MP, Norgaard JP, Rosen RC, McKinlay JB. Nocturia and quality of life: results from the Boston area community health survey. Eur Urol. 2012;61(1):78-84.

30. Gannon K, Glover L, O’Neill M, Emberton M. Men and chronic illness: a qualitative study of LUTS. J Health Psychol. 2004:9(3):411-20.

31. Suen LKP, Cheng HL, Yeung SKW, Au-Yeung CH, Lee JCY, Ho KKY, et al. Qualitative insights into the experiences of living with moderate-to-severe lower urinary tract symptoms among community-dwelling ageing males. PLoS One. 2017;12(10):e0187085.

32. Schubert CR, Cruickshanks KJ, Dalton DS, Klein BE, Klein R, Nondahl DM. Prevalence of sleep problems and quality of life in an older population. Sleep. 2002;25(8):48-52.

33. Zammit GK, Weiner J, Damato N, Sillup GP. McMillan CA. Quality of life in people with insomnia. Sleep: Journal of Sleep Research \& Sleep Medicine; 1999.

34. Carey TJ, Moul DE, Pilkonis P, Germain A, Buysse DJ. Focusing on the experience of insomnia. Behav Sleep Med. 2005:3(2):73-86.

35. Rezaie L, Khazaie $H$, Yazdani F. Exploration of the experience of living with chronic insomnia: a qualitative study. Sleep Sci. 2016:9(3):179-85.

36. Franzen PL, Buysse DJ, Dahl RE, Thompson W, Siegle GJ. Sleep deprivation alters pupillary reactivity to emotional stimuli in healthy young adults. Biol Psychol. 2009:80(3):300-5.

37. Kido K, Hatakeyama S, Imai A, Yamamoto H, Tobisawa Y, Yoneyama T, et al. Sleep disturbance has a higher impact on general and mental quality of life reduction than Nocturia: results from the community health survey in Japan. European urology focus. 2018.

\section{Publisher's Note}

Springer Nature remains neutral with regard to jurisdictional claims in published maps and institutional affiliations.

Ready to submit your research? Choose BMC and benefit from:

- fast, convenient online submission

- thorough peer review by experienced researchers in your field

- rapid publication on acceptance

- support for research data, including large and complex data types

- gold Open Access which fosters wider collaboration and increased citations

- maximum visibility for your research: over $100 \mathrm{M}$ website views per year

At BMC, research is always in progress.

Learn more biomedcentral.com/submission 